\title{
Ankle-Brachial Index as a Predictor of Cardiovascular Risk in Atrial Fibrillation
}

\author{
Carmelo Radellini ${ }^{2}$, Egle Corrado ${ }^{1}$, Giuseppe Coppola ${ }^{2}$, Giuseppina $\mathrm{Novo}^{1}$ and Salvatore Novo ${ }^{2 *}$
}

${ }^{1}$ Chair of Cardiovascular Disease, Center for the Early Diagnosis of Preclinical and Multifocal Atherosclerosis, The Secondary Prevention, University of Palermo, Italy ${ }^{2}$ Division of Cardiology, Department of Internal Medicine and Cardiovascular Disease, Hospital "P. Giaccone" of Palermo, Italy

\begin{abstract}
Objectives: Atrial Fibrillation (AF), the most frequent sustained arrhythmia, is associated with a high rate of morbidity and mortality. The clinical course of AF is often complicated by cardiovascular and cerebrovascular adverse events that usually have a dual origin: cardio embolic and atherothrombotic. The aim of our study is to demonstrate the existence of a relationship between Systemic Atherosclerosis and AF. More specifically, we have analysed the prevalence of lower limb Peripheral Artery Disease (PAD) in a population of fibrillating patients, and we have assessed whether the coexistence of AF and PAD might result in increased cardiovascular risks.

Methods: The study has been conducted on 200 patients, consecutively engaged, divided into patients with and without AF. All patients were subjected to a cardiovascular risk profile evaluation, a measurement of Ankle-BrachialIndex $(\mathrm{ABI})$, and an estimation of the prevalence of cerebrovascular and cardiovascular events.

Results: The obtained results showed that the prevalence of PAD is higher in patients with $A F$, and these patients have also shown a higher prevalence of cerebrovascular and cardiovascular events. In addition, stratifying cases and controls according to the presence of PAD, we showed that there's a higher prevalence of cardiovascular and cerebrovascular adverse events in people with both conditions associated.

Conclusions: The results affirm that patients with a history of AF have a higher rate of cerebrovascular disease, and patients with $P A D$ and $A F$ have a higher rate of coronary disease, suggesting that measurements of $A B I$ and diagnosis and search for AF should be encouraged.
\end{abstract}

Keywords: Atrial fibrillation; Peripheral artery disease; Ankle brachial index

\section{Introduction}

Atrial Fibrillation (AF) is the most frequent sustained arrhythmia, with a case record of a little less than $1 \%$ in general population, and with a incidence of $0.2 \%$ per year [1]. It is associated with a high rate of morbidity and mortality, requiring massive use of health resources. In particular, AF is a risk factor for deathly and non-deathly ischemic cardiovascular and cerebrovascular events [2,3] probably coming from thromboembolic and atherothrombotic processes [4].

Many traditional cardiovascular risk factors (such as arterial hypertension, diabetes mellitus, obesity and smoking) are connected, in fact, with AF [5]. Recently, other risk factors (such as the high concentration of inflammatory markers in blood) have been associated with AF [6]. We can assume that the background of high "global cardiovascular risk" in which AF emerges, could affect the clinical outcome of patients. It is less defined, instead, the"pro-atherosclerotic" role of arrhythmia itself.

The aim of our study is, first of all, to evaluate the prevalence of PAD in a sample of patients with AF. Furthermore, for each of them the global cardiovascular risk profile and the incidence of every risk factor has been evaluated.

The early conjecture is that the AF, by its variability in cardiac output, could constitute an "independent" risk factor for the acceleration of pluridistrictual atherosclerotic disease. From this perspective, time gains a crucial importance, in terms of length of the arrhythmia.

In the end, we have considered whether the association between $\mathrm{AF}$ and PAD in the sample of patients under analysis could represent or not a higher atherothrombotic risk (prevalence of an attendant chronic coronary and/or cerebrovascular disease) in front of AF and PAD considered apart.

\section{Materials and Methods}

Our study consists of observations conducted on patients arriving for a clinical examination in the Cardiology Division of "Paolo Giaccone" Polyclinic, in Palermo (Italy), between January and June 2011. We have included in the observation subjects older than 18 , with and without AF. Fibrillating patients have been considered as affected by non-valvular AF, as they were not affected by an acquired or congenital valvular disease (such as stenosis, moderate or severe mithralic deficiency, valve substitution). Furthermore, we have excluded patients with AF and hyperthyroidism, subjects with EF (Ejection Fraction) $<55 \%$ and patients with recent or ongoing ACS (Acute Coronary Syndrome).

We have sampled a population of 200 patients, divided into two groups: a "Cases" group, made of patients with $\mathrm{AF}$ and/or an ongoing $\mathrm{AF}$, and a "Controls" group, made of subjects with normal Sinus

${ }^{*}$ Corresponding author: Prof. Salvatore Novo, Division of Cardiology Department of Internal Medicine and Cardiovascular Disease, Hospital "P. Giaccone", Via Vespro, 29 - 90127 Palermo, Italy, Tel: $3356889090-$ 0916554301; E-mail: salvatore.novo@unipa.it

Received February 13, 2012; Accepted November 24, 2012; Published Novembe 27, 2012

Citation: Radellini C, Corrado E, Coppola G, Novo G, Novo S (2012) AnkleBrachial Index as a Predictor of Cardiovascular Risk in Atrial Fibrillation. J Clin Exp Cardiolog 3:224. doi:10.4172/2155-9880.1000224

Copyright: (C) 2012 Radellini C, et al. This is an open-access article distributed under the terms of the Creative Commons Attribution License, which permits unrestricted use, distribution, and reproduction in any medium, provided the original author and source are credited. 
Rhythm (SR), without AF and without any arrhythmic events in the ECG control during last 24 hours.

Afterwards, we have divided Cases and Controls according to the lack or presence of PAD, thus identifying four subgroups: Cases with PAD, Controls with PAD, Cases without PAD, Controls without PAD. In the end, according to the ESC 2010 guide-lines, we have stratified the presence of $\mathrm{AF}$ in paroxysmal, persistent and permanent [7].

The study was approved by the local ethics committee and all patients expressed their informed consent to the participation to the study. Then, we have submitted them to anamnesis, to estimate the eventual CVD familiarity and the presence of major CVD risk factors. We have carefully evaluated also body weight, height, arterial pressure and heart rate of all patients, and each of them has provided a blood sample for a blood chemistry test. The eventual CVD familiarity has been defined only in the presence of a coronary disease imputable to the subject's father before the age of 55 and to the subject's mother before the age of 65 . The prevalence of preexistent cardiovascular or cerebrovascular events has been investigated according to the documentation shown at the moment of the admission to the hospital and according to the reported clinical history.

Arterial pressure was measured in the right arm, with the patient in the sitting position, using a standard sphygmomanometer, after 4 minutes of rest; 2 consecutive readings were taken and the average of the 2 used. Subjects with a systolic pressure $\geq 140 \mathrm{mmHg}$, or a diastolic pressure $\geq 90 \mathrm{mmHg}$, or currently taking medication, were considered hypertensive [8].

Height and weight were measured using a staturimeter and a weighing scale. Body Mass Index was calculated as the ratio between height and weight. Obesity was defined as having BMI $\geq 30 \mathrm{~kg} / \mathrm{m}^{2}$ [9]

In line with the $\mathrm{ADA}$, subjects having regular hypoglycemic or insulin treatment were considered diabetic, as were subjects exhibiting glycaemia $>126 \mathrm{mg} / \mathrm{dl}[10]$.

Total Cholesterol (TC), HDL-cholesterol (HDL-C) and triglycerides (TG) were quantified using enzymatic-colorimetric methods, whilst LDL-cholesterol (LDL-C) was calculated using the Friedewald formula. Subjects with cholesterol $\geq 190 \mathrm{mg} / \mathrm{dl}$, or receiving treatment, were considered hypercholesterolemia [11].

\section{Valuation of lower limb peripheral artery disease}

The incidence of PAD was evaluated using $\mathrm{ABI}$ or the Winsor index. $\mathrm{ABI}$ measurement is simple and inexpensive, requiring the use of a standard sphygmomanometer and a portable Doppler unit with probe set at $8 \mathrm{MHz}$. The $\mathrm{ABI}$ is the ratio between the systolic pressure measured on the lower limb and the systolic pressure measured on the arm. We have used the higher pressure between the pedidial anterior and tibial posterior arteries. The index was calculated from the ratio between the lower limb pressure and ipsilateral humeral pressure.

In normal conditions, the pressure measured in the calf is slightly higher than that measured in the arm; consequently, an $\mathrm{ABI}$ value close to 1 indicates a healthy vascular system.

Higher values $(>1.30)$ could indicate the presence of less flexible arteries due to thickening or hardening of the artery wall - a common condition in diabetics. Also in asymptomatic patients, values $<0.90$ are considered as a cut-off point to confirm a diagnosis of iliac-femoralpopliteal atherosclerosis [12].

In our study we have adopted the following interpretation:

$\mathrm{ABI}>1.30=$ non-squeezable artery

ABI between 0.91 and $1.30=$ normal

$\mathrm{ABI}$ between 0.41 and $0.90=$ light or moderate artery obstruction disease

$\mathrm{ABI}$ between 0.00 and $0.40=$ severe artery obstruction disease

\section{Statistical analysis}

This analysis was made using the Stratview program (Abacus Concepts Inc.). We have calculated the average and standard deviation for numerical variables and we have obtained the differences between the groups using the "T" test by Student or by variance analysis (ANOVA) where there were more than two groups to consider. Prevalence of several clinical and laboratory variables was calculated, and the difference between the groups obtained using the $\chi^{2}$ statistical test. The statistical incidence is considered for values of $p<0.05$. To evaluate the variables independently associated with cerebrovascular and cardiovascular events, we have built a logistic regression model by applying uni-variant analysis to the significant results. The results of this model are expressed as Odds Ratio (OR) with $95 \%$ confidence.

\section{Results}

The principal clinical characteristics of the two groups are shown on table 1 (Cases vs. Controls).The 'Cases' group comprised a total of

\begin{tabular}{|c|c|c|c|}
\hline & Cases $(n=100)$ & Controls $(n=100)$ & $p$ value $<0.05$ \\
\hline Age ( $n \pm S D)$ & $74.78 \pm 9.23$ & $72.83 \pm 9.19$ & 0.23 \\
\hline Males & $53 \%$ & $55 \%$ & 0.89 \\
\hline Females & $47 \%$ & $45 \%$ & 0.89 \\
\hline Hypertension & $91 \%$ & $92 \%$ & 0.99 \\
\hline Diabetes mellitus & $48 \%$ & $40 \%$ & 0.32 \\
\hline Hypercholesterolemia & $37 \%$ & $35 \%$ & 0.88 \\
\hline Smoking & $34 \%$ & $30 \%$ & 0.65 \\
\hline Obesity & $16 \%$ & $14 \%$ & 0.84 \\
\hline Familiarity for CVD & $19 \%$ & $20 \%$ & 0.99 \\
\hline$A B I(n \pm D S)$ & $0.95 \pm 0.18$ & $0.97 \pm 0.14$ & 0.37 \\
\hline PAD & $42 \%$ & $27 \%$ & 0.037 \\
\hline Coronary artery disease & $49 \%$ & $26 \%$ & 0.0013 \\
\hline Cerebrovascular disease & $34 \%$ & $16 \%$ & 0.0055 \\
\hline
\end{tabular}

CVD: Cardiovascular Disease; ABI: Ankle Brachial Index; PAD: Peripheral Artery Disease

Table 1: Clinical characteristics of "Cases" group (fibrillating patients) and "Controls" group (Sinusal Rhythm) 
Citation: Radellini C, Corrado E, Coppola G, Novo G, Novo S (2012) Ankle-Brachial Index as a Predictor of Cardiovascular Risk in Atrial Fibrillation. J Clin Exp Cardiolog 3:224. doi:10.4172/2155-9880.1000224

Page 3 of 5

100 patients, 55 male and 45 female, with an average age of $72.8( \pm 9.2)$ years. The two groups were homogeneous for average age, distribution between sexes and the cardiovascular risks analyzed.

Within the entire test population, there was evidence of an incidence of PAD (defined as ABI < 0.9) of 34.5\%. Although the average $\mathrm{ABI}$ value was largely applicable to both groups $(0.95 \pm 0.18 \mathrm{vs}$. $0,97 \pm 0,14)$, the incidence of PAD appears significantly higher in the Cases group with respect to the Control group ( $42 \%$ vs $27 \%$; $\mathrm{p}=0.037$ ).

\begin{tabular}{|c|c|c|c|c|c|}
\hline & $\begin{array}{l}\text { Cases with PAD } \\
(n=42)\end{array}$ & $\begin{array}{l}\text { Controls with PAD } \\
(n=27)\end{array}$ & $\begin{array}{l}\text { Cases without PAD } \\
(\mathrm{n}=58)\end{array}$ & $\begin{array}{l}\text { Controls without PAD } \\
(n=73)\end{array}$ & $\begin{array}{l}P \text { value } \\
<0.05\end{array}$ \\
\hline Age (n $\pm S D)$ & $72.6 \pm 9.73$ & $74.22 \pm 9.7$ & $75.45 \pm 8.75$ & $72.1 \pm 8.99$ & 0.18 \\
\hline Males & $23(54.76 \%)$ & $15(55.55 \%)$ & $30(51.72 \%)$ & $40(54.79 \%)$ & 0.98 \\
\hline Females & $19(45.24 \%)$ & $12(44.45 \%)$ & $28(49.12 \%)$ & $33(45.2 \%)$ & 0.98 \\
\hline Hypertension & $35(83.33 \%)$ & $25(92.59 \%)$ & $56(96.55 \%)$ & $67(91.78 \%)$ & 0.13 \\
\hline Diabetes mellitus & $20(47.61 \%)$ & $21(77.77 \%)$ & $28(48.27 \%)$ & $19(26.02 \%)$ & $<0.0001$ \\
\hline Hypercholesterolemia & $19(45.23 \%)$ & $22(81.48 \%)$ & $18(31.03 \%)$ & $13(17.80 \%)$ & $<0.0001$ \\
\hline Smoking & $15(35.71 \%)$ & $20(74.07 \%)$ & $19(32.75 \%)$ & $10(13.69 \%)$ & $<0.0001$ \\
\hline Obesity & $5(11.90 \%)$ & $7(25.92 \%)$ & $11(18.96 \%)$ & $7(9.59 \%)$ & 0.15 \\
\hline Familiarity for CVD & $10(2.38 \%)$ & $5(18.52 \%)$ & $9(15.52 \%)$ & $15(20.54 \%)$ & 0.76 \\
\hline Coronary artery disease & $28(66.66 \%)$ & $12(44.44 \%)$ & $21(36.20 \%)$ & $14(19.18 \%)$ & $<0.0001$ \\
\hline Cerebrovascular disease & $16(38.09 \%)$ & $9(33.33 \%)$ & $18(31.03 \%)$ & $7(9.59 \%)$ & 0.0016 \\
\hline
\end{tabular}

CVD: Cardiovascular Disease; PAD: Peripheral Artery Disease

Table 2: Clinical characteristics of Cases and Controls groups stratified according to the lack or presence of PAD.

\begin{tabular}{|c|c|c|c|}
\hline & Cerebrovascular events $(n=50)$ & Not Cerebrovascular events $(n=150)$ & $p$ value $<0.05$ \\
\hline Age $(n \pm S D)$ & $74.40 \pm 9.69$ & $73.15 \pm 9.07$ & 0.41 \\
\hline Males & $26(52 \%)$ & $82(54.6 \%)$ & 0.87 \\
\hline Females & $24(48 \%)$ & $68(45.3 \%)$ & 0.87 \\
\hline Hypertension & $47(94 \%)$ & $136(90.67 \%)$ & 0.66 \\
\hline Diabetes mellitus & $23(46 \%)$ & $65(43.33 \%)$ & 0.87 \\
\hline Hypercholesterolemia & $17(34 \%)$ & $55(36.67 \%)$ & 0.86 \\
\hline Smoking & $17(34 \%)$ & $47(31.33 \%)$ & 0.86 \\
\hline Obesity & $10(20 \%)$ & $20(13.33 \%)$ & 0.36 \\
\hline Familiarity for CVD & $11(22 \%)$ & $28(18.67 \%)$ & 0.76 \\
\hline$A B I(n \pm S D)$ & $0.91 \pm 0.18$ & $0.96 \pm 0.16$ & 0.047 \\
\hline PAD + AF & $16(32 \%)$ & $26(17.33 \%)$ & 0.045 \\
\hline AF - PAD & $18(68 \%)$ & $40(27 \%)$ & 0.28 \\
\hline SR + PAD & $9(18 \%)$ & $18(12 \%)$ & 0.40 \\
\hline SR - PAD & $7(14 \%)$ & $66(44 \%)$ & 0.0003 \\
\hline Cardiovascular events & $20(40 \%)$ & $30(20 \%)$ & 0.80 \\
\hline
\end{tabular}

CVD: Cardiovascular Disease; ABI: Ankle Brachial Index; AF: Atrial Fibrillation; PAD: Peripheral Artery Disease; SR: Sinus Rhythm; AF + PAD: Presence of AF and PAD: $A F$ - PAD Presence of AF/absence of PAD; SR + PAD: Presence of PAD/ absence of AF; SR - PAD: Absence of PAD and AF

Table 3: Clinical characteristics of the population stratified according to the lack or presence of cerebrovascular events in the clinical history.

\begin{tabular}{|c|c|c|c|}
\hline & Cardiovascular events $(n=75)$ & Not Cardiovascular events $(n=125)$ & $p$ value $<0.05$ \\
\hline Age $(n \pm S D)$ & $74.13 \pm 9.02$ & $73.06 \pm 9.35$ & 0.43 \\
\hline Males & $41(55 \%)$ & $67(53.6 \%)$ & 0.1 \\
\hline Females & $34(45.33 \%)$ & $58(46.4 \%)$ & 0.1 \\
\hline Hypertension & $68(90.67 \%)$ & $115(92 \%)$ & 0.95 \\
\hline Diabetes mellitus & $33(44 \%)$ & $55(44 \%)$ & 0.88 \\
\hline Hypercholesterolemia & $37(49.33 \%)$ & $35(28 \%)$ & 0.004 \\
\hline Smoking & $24(32 \%)$ & $40(32 \%)$ & 0.87 \\
\hline Obesity & $8(10.67 \%)$ & $22(17.6 \%)$ & 0.26 \\
\hline Familiarity for CVD & $12(16 \%)$ & $27(21.6 \%)$ & 0.43 \\
\hline$A B I(n \pm S D)$ & $0.89 \pm 0.14$ & $0.99 \pm 0.18$ & $<0.0001$ \\
\hline PAD + AF & $28(37.33 \%)$ & $14(11.2 \%)$ & $<0.0001$ \\
\hline AF - PAD & $21(28 \%)$ & $37(29.6 \%)$ & 0.93 \\
\hline SR + PAD & $12(16 \%)$ & $15(12 \%)$ & 0.55 \\
\hline SR - PAD & $14(18.67 \%)$ & $59(47.2 \%)$ & 0.0001 \\
\hline Cerebrovascular events & $20(40 \%)$ & $55(44 \%)$ & 0.8 \\
\hline
\end{tabular}

CVD: Cardiovascular Disease; ABI: Ankle Brachial Index; AF: Atrial Fibrillation; PAD: Peripheral Artery Disease; SR: Sinus Rhythm; AF + PAD: Presence of AF and PAD; $A F$ - PAD: Presence of AF/absence of PAD; SR + PAD: Presence of PAD/ absence of AF; SR - PAD: Absence of PAD and AF.

Table 4: Clinical characteristics of the population stratified according to the lack or presence of cardiovascular events in the clinical history. 
Similarly, the prevalence of chronic coronary disease ( $49 \%$ vs $26 \% ; \mathrm{p}=$ $0.0013)$, and chronic CVD ( $34 \%$ vs. $16 \% ; \mathrm{p}=0.0055)$ appears higher in patients with ongoing or recent $\mathrm{AF}$.

On table 2 we have reported and compared clinical conditions of the sampled patients, divided into the following subgroups: cases with PAD $(n=42)$, controls with PAD $(n=27)$, Cases without PAD $(n=58)$, Controls without PAD $(n=73)$. From the results emerged a statistical incidence for diabetes mellitus $(\mathrm{p}<0.0001)$, hypercholesterolemia ( $\mathrm{p}<0.0001)$, and smoking $(\mathrm{p}<0.0001)$ - risk factors definitely more represented in the "Controls with PAD" subgroup (Figure 1). We have to underline also an important statistical incidence in cerebrovascular and cardiovascular events $(\mathrm{p}=0.0016 ; \mathrm{p}<0.0001)$, both of them mostly represented in the "Cases with PAD" subgroup (Figure 2). Again, to evaluate the variables independently associated with cerebrovascular and cardiovascular events, we have built a logistic regression model, using a uni-variant analysis system on the sample of patients, stratified in advance according to the lack or presence of cerebrovascular (Table 3) and cardiovascular (Table 4) adverse events, underlining variables with a statistical incidence. From this analysis emerged that the Sinusal Rhythm (OR $=0.20$; 95\% IC 0.09-0.48) constitutes a protective factor from cerebrovascular events $(\mathrm{p}=0.0003)$ (Table 5). Independent predictors of cardiovascular events seem to be, indeed, the coexistence of $\mathrm{AF}$ and $\mathrm{PAD}(\mathrm{p}<0.0001 ; \mathrm{OR}=4.67 ; 95 \%$ IC 2.22 9.82) and hypercholesterolemia $(\mathrm{p}=0.005 ; \mathrm{OR}=2.47 ; 95 \%$ IC $1.31-4.64)$ (Table 6).

In the Cases group, patients were ordered according to the atrial fibrillation grade: paroxysmal $(n=12)$, persistent $(n=36)$ and permanent $(n=52)$. No statistical incidence emerged for almost all of the variables considered. PAD resulted slightly more frequent in patients with persistent AF (47.22\% persistent vs. $40.38 \%$ permanent vs. $33.33 \%$ paroxystic). This trend hasn't a statistical incidence, anyway. The prevalence of coronary and chronic cerebrovascular disease resulted, indeed, significantly higher in patients with permanent AF (respectively p=0.02 e p=0.01) (Table 7).

\section{Discussion}

Many patients with AF show an increased risk of atherothrombosis

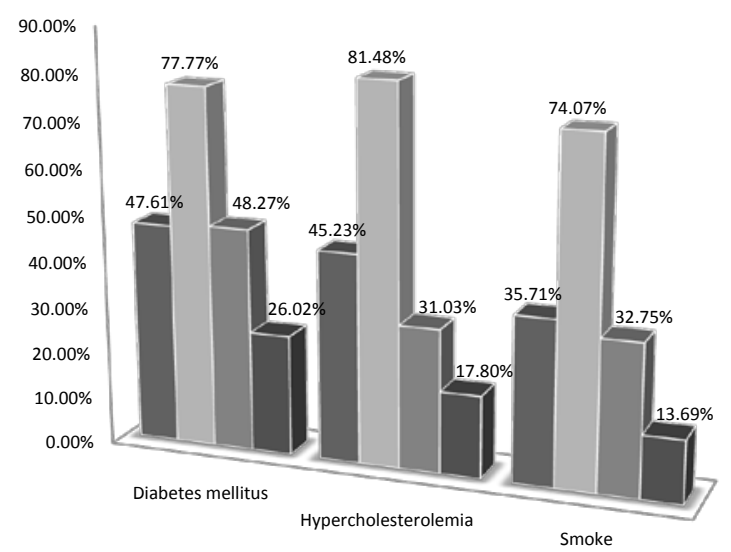

A: Cases with PAD

B: Controls with PAD

C: Cases without PAD

D: Controls without PAD

Figure 1

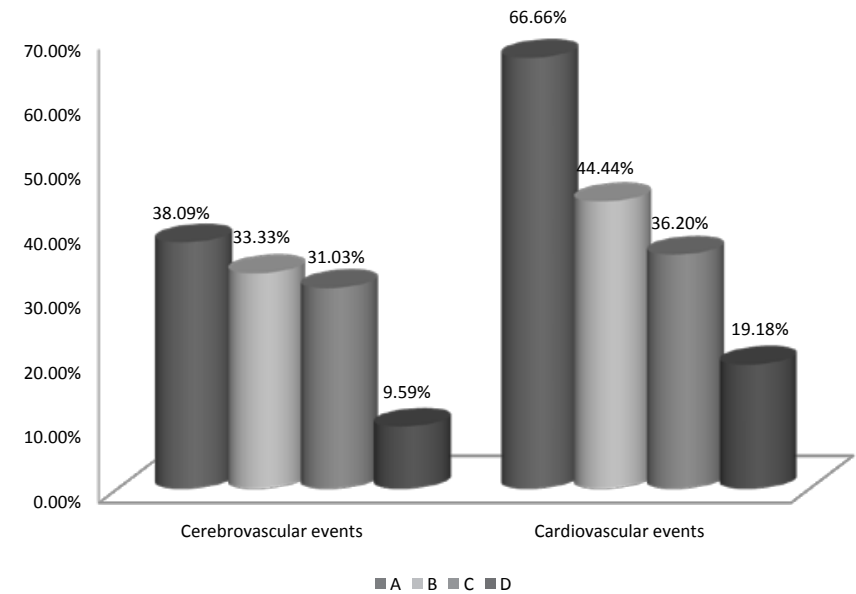

A: Cases with PAD

B: Controls with PAD

C: Cases without PAD

D: Controls without PAD

Figure 2

\begin{tabular}{|llll|}
\hline Variables & OR & $\mathbf{9 5 \%} \mathbf{~ C I}$ & P-value<0.05 \\
\hline ABI & 0.41 & $0.032-5.14$ & 0.4882 \\
\hline PAD\&AF & 1.13 & $0.48-2.68$ & 0.7741 \\
\hline Hypercholesterolemia & 0.53 & $0.25-1.12$ & 0.0964 \\
\hline Sinus Rhythm & 0.20 & $0.87-0.48$ & $\mathbf{0 . 0 0 0 3}$ \\
\hline
\end{tabular}

OR: Odds Ratio; Cl: Confidence Interval

Table 5: Logistic regression Analysis. Predictive variables of cerebrovascular events.

\begin{tabular}{|llll|}
\hline Variables & OR & $\mathbf{9 5 \%} \mathbf{C I}$ & P-value $<0.05$ \\
\hline ABI & 0.14 & $0.01-1.67$ & 0.1191 \\
\hline Sinus Rhythm & 0.55 & $0.25-1.19$ & 0.1313 \\
\hline PAD\&AF & 4.67 & $2.22-9.82$ & $<0.0001$ \\
\hline Hypercholesterolemia & 2.47 & $1.31-4.63$ & $\mathbf{0 . 0 0 5}$ \\
\hline
\end{tabular}

OR: Odds Ratio; Cl: Confidence Interval; AF: Atrial fibrillation; PAD: Periphera artery disease

Table 6: Logistic regression Analysis. Predictive variables of cardiovascular events

due to various atherosclerosis factors that also increase the AF risk. In a recent prospective study, 14.598 middle-aged subjects, participants in the 'Atherosclerosis Risk in Communities' study (ARIC), were followed for 17 years. Of these, $56.5 \%$ of the 'Cases of AF' could be explained by the presence of multiple borderline or high risks. Among these, hypertension plays a dominant role [5]. Less clear, however, is the role played by AF as an independent factor in the development of atherosclerosis. In our study, even though the test population was fairly homogeneous with regard to the cardiovascular risks in the background, emerged a statistically important connection between $\mathrm{AF}$ and pluridistrictual atherosclerosis. Contrary to those patients with a sinusal rhythm, the group of fibrillating showed a greater prevalence of lower limb Obstructive Artery Disease and a greater prevalence of ischemic coronary and cerebrovascolar disease in their clinical histories. It is interesting to note, focusing only on the group of patients with PAD (both fibrillating and non), how we can see a trend to higher prevalence of risk factors in non-fibrillating PAD patients. The association between $\mathrm{AF}$ and $\mathrm{PAD}$ seems to cause an increased atherothrombotic coronary risk compared to the individual risk from 
Citation: Radellini C, Corrado E, Coppola G, Novo G, Novo S (2012) Ankle-Brachial Index as a Predictor of Cardiovascular Risk in Atrial Fibrillation. J Clin Exp Cardiolog 3:224. doi:10.4172/2155-9880.1000224

Page 5 of 5

\begin{tabular}{|c|c|c|c|c|}
\hline & Paroxysmall $(n=12)$ & Persistent $(n=36)$ & Permanent $(n=52)$ & $P$ value \\
\hline Age ( $n \pm S D)$ & $74.9 \pm 6.2$ & $72.1 \pm 8.9$ & $75.7 \pm 9.3$ & 0.19 \\
\hline Sex & $\begin{array}{l}\text { M } 6(50 \%) \\
\text { F } 6(50 \%)\end{array}$ & $\begin{array}{l}\text { M } 19(52.8 \%) \\
\text { F } 17(47.2 \%)\end{array}$ & $\begin{array}{l}\text { M } 28(54.9 \%) \\
\text { F } 24(45.1 \%)\end{array}$ & 0.97 \\
\hline Hypertension & $12(100 \%)$ & $33(91.7 \%)$ & $46(88.46 \%)$ & 0.44 \\
\hline Diabetes mellitus & $7(58.3 \%)$ & $16(44.44 \%)$ & $25(48.08 \%)$ & 0.70 \\
\hline Hypercholesterolemia & $5(41.7 \%)$ & $13(36.11 \%)$ & $19(36.54 \%)$ & 0.93 \\
\hline Smoking & $3(25 \%)$ & $14(38.9 \%)$ & $17(32.69 \%)$ & 0.65 \\
\hline Obesity & $1(8.3 \%)$ & $5(13.9 \%)$ & $10(19.23 \%)$ & 0.59 \\
\hline Familiarity for CVD & 0 & $7(19.44 \%)$ & $12(23.08 \%)$ & 0.18 \\
\hline PAD & $4(33.33 \%)$ & $17(47.22 \%)$ & $21(40.38 \%)$ & 0.66 \\
\hline$A B I$ & $0.89 \pm 0.16$ & $0.94 \pm 0.18$ & $0.95 \pm 0.17$ & 0.64 \\
\hline Coronary artery disease & $3(25 \%)$ & $14(38.88 \%)$ & $32(61.53 \%)$ & 0.023 \\
\hline Cerebrovascular disease & $4(33.3 \%)$ & $12(32.4 \%)$ & $18(35.3 \%)$ & 0.01 \\
\hline
\end{tabular}

PAD: Peripheral Artery Disease; ABI: Ankle-Brachial-Index

Table 7: Clinical characteristics of Cases group stratified by AF grade.

each of them: AF without PAD and PAD without AF. Other authors have confirmed the negative impact of such a connection in prognosis [13].

Unexpectedly, considering the variability in cardiac output as a possible cause of atherosclerosis independent of other risk factors, PAD results more representative in the sub-group of patients with persistent AF rather than in those with permanent AF. The scope of our study is however limited by the size of the patient group and therefore not suitable for validating physiopathological consequences. Additional evidence is required to clarify the existence of and the mechanisms for increased atherothrombotic risk from AF.

\section{Conclusions}

The results obtained show that patients with AF have an increased risk of cerebrovascular events, and patients with $\mathrm{AF}$ and PAD have an increased risk of coronary disease, thus suggesting that measuring $\mathrm{ABI}$ and diagnosis of, and research into, AF should be encouraged.

\section{References}

1. Go AS, Hylek EM, Philips KA, Chang Y, Henault LE, et al. (2001) Prevalence of diagnosed atrial fibrillation in adults: national implications for rhytm management and stroke prevention: the An Ticoaugulation and Risk Factors in Atrial fibrillation (ATRIA) study. JAMA 285: 2370-2375.

2. Kannel WB, Abbott RD, Savage DD, McNamara PM (1983) Coronary heart disease and atrial fibrillation: the Framingham Study. Am Heart J 106: 389-396.

3. Steinberg JS, Sadaniantz A, Kron J, Krahn A, Denny DM, et al. (2004) Analysis of cause-specific mortality in the Atrial Fibrillation Follow-up Investigation of Rhytm Management (AFFIRM) study. Circulation 109: 1973-1980.

4. Depta JP, Bhatt DL (2010) Atherothrombosis and atrial fibrillation : important and often overlapping clinical syndromes. Thromb Haemost 104: 657-663.

5. Huxley RR, Lopez FL, Folsom AR, Agarwal SK, Loehr LR, et al. (2011) Absolute and attributable risks of atrial fibrillation in relation to optimal and borderline risk factors: the Atherosclerosis Risk in Communities (ARIC) study. Circulation 123 1501-1508.

6. Aviles RJ, Martin DO, Apperson-Hansen C, Houghtaling PL, Rautaharju P, et al. (2003) Inflammation as a risk factor for atrial fibrillation. Circulation 108: 3006-3010.

7. Camm AJ, Kirchof P, Lip GY, Schotten U, Savelieva I, et al. (2010) Guidelines for the management of atrial fibrillation : the task force for the management of atrial fibrillation of the European Socety of Cardiology (ESC). Eur Heart J 31: 2369-2429.

8. Mancia G, De Backer G, Dominiczak A, Cifkova R, Fagard R, et al. (2007) 2007 Guidelines for the management of arterial hypertension : The Task Force for the Management of Arterial Hypertension of the European Society of Hypertension (ESH) and of the European Society of Cardiology (ESC). Eur Heart J 28: 1462-1536.

9. Alberti KG, Eckel RH, Grundy SM, Paul Z Zimmet, James I Cleeman, et al. (2009) Harmonizing the metabolic syndrome: a joint interim statement of the International Diabetes Federation Task Force on Epidemiology and Prevention National Heart, Lung, and Blood Institute; American Heart Association; World Heart Federation; International Atherosclerosis Society; and Internationa Association for the Study of Obesity. Circulation 120: 1640-1645.

10. American Diabetes Association (2008) Report of the expert committee on the diagnosis and classification of Dabetes Mellitus. Diabetes Care 31: S5-S11.

11. Graham I, Atar D, Borch-Johnsen K, Boysen G, Burell G, et al. (2007) European guidelines on cardiovascular disease prevention in clinical executive summary. Fourth Joint, Task Force of the European Society of Cardiology and other societies on Cardiovascular Disease Prevention in Clinical Practice (Constituted by representatives of nine societies and by invited experts). Eur Heart J 28: 2375-2414

12. Perlstein TS, Creager MA (2009) The ankle-brachial-index as a biomarker of cardiovascular risk : it's not just about the legs. Circulation 120: 2033-2035.

13. Violi F, Lip GY, Basili S (2011) Peripheral artery disease and atrial fibrillation : a potentially dangerous combination. Inter Emerg Med 7: 213-218. 